\title{
Original article (short paper) \\ Maximum number of repetitions performed by resistance-trained men: Effect of maximum load intensity and exercise selection
}

\author{
Charles R. Lopes \\ Alex H. Crisp \\ Rozangela Verlengia \\ Methodist University of Piracicaba, Brazil \\ Cesar A. Macarrone \\ Dyego A. Peghim \\ Adventist Faculty of Hortolandia, Brazil \\ Gustavo R. Mota \\ Federal University of Triangulo Mineiro, Brazil \\ Marcelo S. Aoki \\ University of São Paulo, Brazil \\ Paulo H. Marchetti \\ Methodist University of Piracicaba, Brazil
}

\begin{abstract}
The purpose of this study was to compare the number of maximum repetitions (RMs) performed at $80 \%$ of one-repetition maximum (1RM) and $80 \%$ of one-repetition maximum eccentric (1RMecc) test for the preacher-curl (PC) and the bench-press (BP) exercises. Fifteen resistance-trained men participated in this counterbalanced-crossover study. There was no significant difference in the number of RMs performed at 80\%-1RM (PC: 7.0 \pm 1.2 RMs and BP: 5.8 $\pm 1.3 \mathrm{RMs}$ ) and 80\%-1RMecc (PC: 6.0 $\pm 1.1 \mathrm{RMs}$ and BP: $5.4 \pm 1.1 \mathrm{RMs}$ ) for both exercises. No significant difference in the numbers of RMs was detected between the PC (80\%-1RM: 7.0 \pm 1.2 RMs and 80\%-1RMecc: $6.0 \pm 1.1 \mathrm{RMs})$ and BP exercises (80\%-1RM: 5.8 $\pm 1.3 \mathrm{RMs}$ and 80\%-1RMecc: $5.4 \pm 1.1 \mathrm{RMs})$ for both intensities. In conclusion, the number of RMs performed by resistance-trained men was not affected by the maximum load intensity based on muscle action and the exercise selection.
\end{abstract}

Keywords: muscle strength, training prescription, concentric, eccentric

Resumo - "Número máximo de repetições realizadas por homens treinados em força: Efeitos da intensidade máxima de carga e escolha do exercício." O objetivo deste estudo foi comparar o número de repetições máximas (RMs) realizadas com intensidade de $80 \%$ dos testes de uma repetição máxima (1RM) e $80 \%$ de uma repetição máxima excêntrica (1RMecc) para os exercícios supino-horizontal (SH) e rosca-scott (RS). Quinze homens com experiência em treinamento de força participaram desse estudo randomizado cruzado. Não houve diferença significativa no número de RMs realizadas a 80\%-1RM (RS: 7,0 $\pm 1,2$ RMs e SH: 5,8 $\pm 1,2$ RMs) e 80\%-1RMecc (RS: 6,0 $\pm 1,1$ RMs e SH: $5,4 \pm 1,1 \mathrm{RMs})$ para ambos os exercícios. Não foi detectada diferença significativa no número de RMs entre o exercício

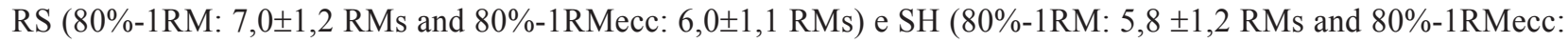
$5,4 \pm 1,1 \mathrm{RMs})$ para ambas intensidades. Em conclusão, o número de RMs realizados por homens treinados em força não foi afetado pela intensidade máxima da carga baseada na ação muscular e pela seleção de exercícios.

Palavras-chave: força muscular, prescrição de treinamento, concêntrico, excêntrico 


\begin{abstract}
Resumen- -El número máximo de repeticiones realizadas por hombres entrenados: efecto de la intensidad de carga máxima y la selección de los ejercicios." El objetivo de este estudio fue comparar el número de repeticiones máximas (RMS) realizado con una intensidad de $80 \%$ de una repetición máxima (1RM) y el $80 \%$ de una repetición máxima excéntrica (1RMecc) para el ejercicio supino horizontal (SH) y rosca scott (RS). Quince hombres con experiencia en el entrenamiento de fuerza participaron en este estudio cruzado aleatorio. No hubo diferencia significativa en el número de los RMs realizado a $80 \% 1 \mathrm{RM}$ (RS: 7,0 $\pm 1,2 \mathrm{RMs}$ e SH: $5,8 \pm 1,2 \mathrm{RMs}$ ) y $80 \%$-1RMecc (RS: $6,0 \pm 1,1$ RMs e SH: $5,4 \pm 1,1$ RMs) para ambos ejercicios. No se detectó diferencia significativa en el número de los RMs entre el ejercicio RS (80\%1RM: 7,0 $\pm 1,2$ RMs and 80\%-1RMecc: 6,0 $\pm 1,1$ RMs) y SH (80\%-1RM: 5,8 $\pm 1,2$ RMs and 80\%-1RMecc: 5,4 $\pm 1,1$ RMs) para ambas intensidades. En conclusión, el número de RMs realizados por hombres entrenados en la fuerza no afectó la intensidad máxima de la carga basada en la acción muscular y la selección de los ejercicios.
\end{abstract}

Palabras clave: la fuerza muscular, prescripción de entrenamiento, concéntrico, excéntrico

\section{Introduction}

The manipulation of acute training variables, such as, choice and order of exercises, intensity, volume, rest interval, velocity of execution and range of motion evokes distinct acute and chronic adaptations in response to resistance training (American College of Sports and Medicine, 2009; Bird, Tarpenning, \& Marino, 2005; Kraemer \& Ratamess, 2004). Among these variables, the load intensity, often prescribed by the one repetition maximum $(1 \mathrm{RM})$ test, plays a key role in optimizing these neuromuscular adaptations. The 1RM test involves the determination of the maximum load for the execution during a single iso-inertial muscle action (eccentric and concentric phases) (Fry, 2004). However, during isolated eccentric actions, the skeletal muscle elicits a higher strength output when compared to isolated concentric actions (Enoka, 1996). Thus, when using the 1RM traditional test (eccentric and concentric phases), the absolute intensity of the load is reduced in eccentric muscle action. In this sense, Smith et al. (2000) emphasized that the 1RM test actually reflects only the maximum capacity that can be exerted for the concentric muscle action. Based on these assumptions, it is reasonable to speculate that the intensity of resistance exercise with isolated eccentric muscle actions prescribed based on a certain percentage of $1 \mathrm{RM}$ test might not provide a proper stimulus in order to enhance expected training adaptations (Brandenburg \& Docherty, 2002; Tan, 1999).

With the purpose of making a more precise determination of the eccentric exercise intensity, Hollander at al., (2007) developed the one repetition maximum eccentric test (1RMecc). These authors demonstrated that depending on the exercise evaluated in trained men, the eccentric muscle action produces $20-60 \%$ greater force output as compared to the concentric muscle action. Therefore, the assessment of maximum eccentric load is crucial to provide a progressive overload especially for trained individuals.

Furtheremore, there is no consensus in the literature on the effect of concentric and eccentric maximum loads on the number of maximum repetitions performed at a given relative intensity. In such studies, another variable that should be considered is the type of exercise performed and the amount of muscle mass involved (Hoeger et al., 1987; Hoeger et al., 1990; Shimano et al., 2006). Hoeger et al. (1990) reported that in the intensity of $80 \%$ of $1 \mathrm{RM}$ test, resistance trained-men were able to perform significantly more repetitions in the leg press exercise, when compared to the exercises that involved lower muscle mass, such as the bench press and arm curl. On the other hand, Shimano et al. (2006) found no significant difference in the back-squat exercise when compared to the bench press and arm curl exercise performed at $80 \%$ of $1 \mathrm{RM}$ test, in resistance trained-men.

Up to now, no previous study has assessed the maximum number of repetitions that can be performed at a selected percentage of the 1RMecc test in different exercises. Therefore, the present study aimed to compare the maximum number of repetitions performed with intensity of $80 \%$ of $1 \mathrm{RM}$ and $1 \mathrm{RMecc}$ tests for the bench press and preacher curl exercises.

\section{Methods}

\section{Participants}

Fifteen young healthy men $(27.2 \pm 2.2$ years; $80.9 \pm 6.2 \mathrm{~kg}$; $176.1 \pm 6.2 \mathrm{~cm}$ ) with experience of $3.4 \pm 2.4$ years of resistance training participated in the study. The number of participants was determined using the data of changes in maximal eccentric strength from the previous pilot study. Fourteen participants was an adequate sample size to meet effect size of 1 , alpha level of 0.05 and a power (1- $\beta$ ) of 0.80 . The inclusion and exclusion criteria for participation in the study were: (a) having at least one year of continuous experience in resistance training; (b) having no previous injury which may interfere with the study; (c) using neither creatine-based nutritional supplement nor anabolic steroids. All the participants completed a health questionnaire and signed an informed consent form after being instructed on the experimental protocol of the research. This study was approved by the Research Ethics Committee of the Methodist University of Piracicaba (Protocol number: 41/12).

\section{Procedures}

The volunteers attended the laboratory on seven distinct moments for the experimental sessions, which were separated by an interval of 48 hours. In the first session, participants were familiarized with the tests and with the cadence of the task movement. The 1RM test was determined on the second and third sessions, while the 1RMecc test was conducted in the fourth and fifth session. The higher load was achieved during one of the previous testing days. On the sixth and seventh sessions, the participants were randomly divided (counterbalanced crossover design), and the number of maximum repetitions for each exercise were assessed. The exercises were performed in the following 
order: bench press and preacher curl. All the participants were strongly encouraged to perform maximum effort during the tests.

\section{Maximum muscle strength-1RM test}

The determination of the maximum muscle strength was assessed via the bench press and preacher curl exercises using the 1RM test (Brow \& Weir, 2001). Briefly, the participants performed 2-3 sets of 5-10 warm-up repetitions with a 40-60\% of estimated 1RM. The 1RM tests were performed at a cadence of 3 seconds for the entire range of motion, with a metronome control ( 60 beats per minute). The 1RM load was determined using 3 to 5 attempts with a rest interval of 5 minutes for each exercise and 10 minutes between them.

\section{Muscle eccentric strength test - 1RMecc}

The bench press 1 RMecc test was determined in the following procedures based on Hollander et al., (2007). Briefly, each participant performed 2-3 sets of 5-10 repetitions with a $40-60 \%$ of $1 \mathrm{RM}$ before the 1RMecc test. After 3-minutes of rest, a single maximum eccentric action for 3 seconds (entire range of motion) was performed. The pace of movement was controlled by a metronome. An investigator checked the range of eccentric motion and the pace of movement. Two safety spotters were responsible for positioning the bar and ensure the safety of the participants. The test was performed with a maximum number of four attempts and with a rest interval of 3-5 minutes.

\section{Repetitions maximum tests}

The maximum repetition tests (ECC/CON and ECC) consisted of only 1 set of each exercise (bench press and preacher curls), and were performed at $80 \%$ of the $1 \mathrm{RM}$ or $1 \mathrm{RMecc}$. The participants were instructed to perform the maximum number of repetitions until failure. The rest interval between exercises was 5 minutes. The execution time of each movement was 3 seconds for the entire range of motion (controlled by metronome at 60 beats per minute), and the pace was accompanied by simultaneous verbal instruction. The maximum eccentric repetition test was performed in an isolated form (3 seconds), requiring the help of two assistants who would return the bar to the starting position in three seconds, while the maximum concentric repetition test was performed for eccentric and concentric phase of movement ( 3 seconds for each muscle action). The test was considered ended when the subjects either could not maintain the pace or fail to execute the movement appropriately.

\section{Statistical analysis}

Normality and homogeneity of variances were confirmed by the Shapiro-Wilk and the Levene test, respectively. All the data are presented as mean \pm standard deviation (SD). Then, a one-way ANOVA with Bonferroni post hoc was used to compare the number of maximum repetitions in the bench press to the number of repetitions in the preacher curl exercises. Reliabili- ty of dependent variables was determined using an intraclass correlation coefficiente (ICC) and coefficient of variation (CV). The significance for statistical analyses was set at $5 \%$.

\section{Results}

\section{$1 R M$ and 1RMecc loads}

The 1RM and 1RMecc measures showed a high test-retest reliability $(\mathrm{ICC}>0.90 ; \mathrm{CV}=2.2-5.2 \%)$. The values of the 1RMecc test (Bench press: $134.8 \pm 25.7 \mathrm{~kg}$ and preacher curl: $95.2 \pm 16.2 \mathrm{~kg})$ was significantly higher $(p<0.05)$ when compared with 1RM test (Bench press: $81.7 \pm 10.4 \mathrm{~kg}$ and preacher curl: $59.1 \pm 8.8 \mathrm{~kg}$ ) for both exercises (Figure 1).

\section{Maximum repetition test}

Figure 2 shows the results of the number of maximum repetitions completed in the bench press and preacher curls, both at $80 \%$ of $1 \mathrm{RM}$ or $1 \mathrm{RMecc}$ tests. The numbers of repetitions maximum in preacher curls exercise by $1 \mathrm{RM}(7.0 \pm 1.0$ repetitions $)$ was no significantly higher $(p>0.05)$ compared with 1 RMecc $(5.8 \pm 1.1$ repetitions). There was no significant difference $(p>0.05)$ in the bench press exercise between 1 RMecc $(5.4 \pm 1.2$ repetitions) and $1 \mathrm{RM}$ (5.8 \pm 1.3 repetitions). When comparing both exercises, there was no significant difference $(p>0.05)$ between 1RMecc and 1RM, for bench press and preacher curls exercises (Figure 2).

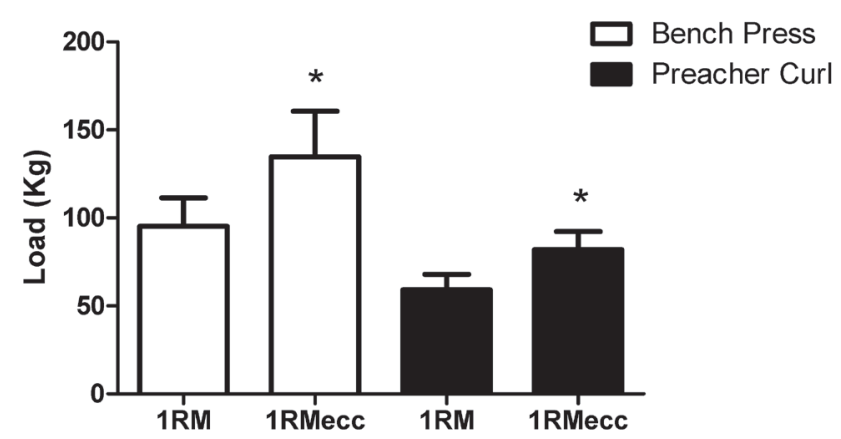

Figure 1. One repetition maximum (1RM) and one repetition maximum eccentric (1RMecc) test for the bench press and the preacher curl exercise. * Significant difference $(p<0.05)$ compared to the 1 RM test. The data are expressed as mean $\pm \operatorname{SD}(n=15)$.

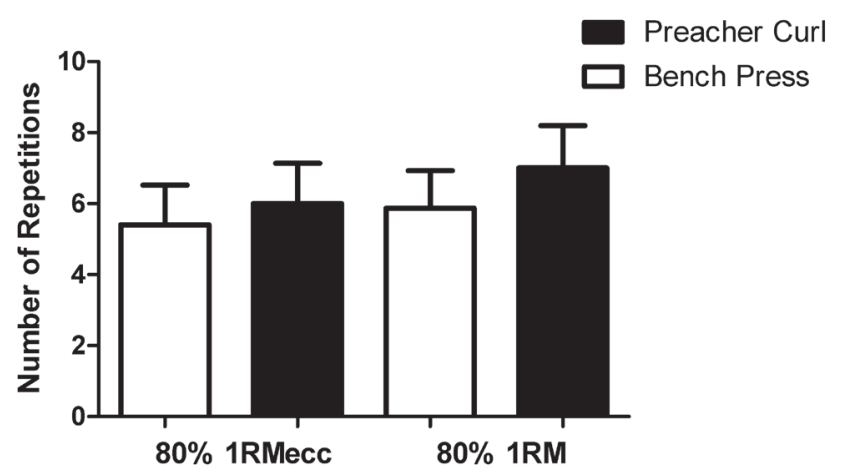

Figure 2. Maximum number of repetitions in the bench press and the preacher curl exercises. The data are expressed as mean $\pm \operatorname{SD}(n=15)$. 


\section{Discussion}

The purpose of this study was to compare the maximum number of repetitions performed with $80 \%$ of the $1 \mathrm{RM}$ and the 1 RMecc for bench press and preacher curl exercises. The main finding was that there was no significant influence of load intensity and exercise selection on the number of repetitions maximum performed by resistance trained men.

The 1RM test represents an important tool for conditioning coaches in the assessment of muscle strength and in the individualization of resistance exercise intensity prescription (Brow \& Weir, 2001). In this context, the absolute values of loads in the 1 RMecc test obtained in the present study were $42 \%$ and $46 \%$ higher than 1 RM test for the bench press and the preacher curl exercises, respectively (Figure 1). These data corroborate the results of Hollander et al. (2007), whose study evaluated the maximal strength by the 1RM and the 1RMecc tests in resistance-trained men and found that eccentric muscle strength was $40 \%$ greater than concentric for bench press exercise. Therefore, these data indicate that for greater accuracy in relation to prescription of eccentric training sessions, a specific muscle strength test for trained individuals is required in order to enhance the training acute stimulus.

Traditionally, the guidelines for prescribing the intensity of resistance training are based on the number of repetitions maximum and the percentage of the maximum load test (American College of Sports and Medicine, 2009; Campos et al., 2002; Kraemer \& Ratmess, 2004). In this regard, the number of repetitions maximum at a selected percent of 1RM test has been investigated at various intensities, exercises, gender and levels of trainability (Hoeger et al., 1987; Hoeger et al., 1990; Shimano et al., 2006). The individuals evaluated in this study performed an average of 5.8 repetitions for the bench press exercise and 7.0 repetitions for the preacher curl performed at $80 \%$ of 1 RM. Results obtained by Hoeger et al. (1990) with the same percentage of intensity included mean values of 12.2 and 11.4 repetitions for the bench press and arm curl exercise, respectively, for trained men. In addition, Shimano et al., (2006) showed mean values of 9.2 repetitions for bench press exercise and 9.1 repetitions for arm curl (trained men). These differences observed in the maximum number of repetitions between studies, probably occurred because the pace of movement, a procedure not utilized in the studies conducted by Hoeger et al. (1990) and Shimano et al. (2006).

Supporting that idea, Sakamoto and Sinclair (2006) evaluated the impact of velocity of execution in different intensities during the bench press exercise. These authors found that, when executing the movement at fast pace, trained individuals performed a higher number of repetitions than when executing the movement at slow pace. The authors explained that the use of stretch-shortening cycle during fast pace movements may have improved the participants' performance (Sakamoto \& Sinclair, 2006). Another important aspect to be considered is the time of muscle tension, which is greater when the movement is performed at slow velocity, requiring greater metabolic demand and inducing early muscle fatigue (Gentil et al., 2006).

Some studies have indicated that the amount of muscle mass involved in exercise can influence the maximum number of repetitions performed (Hoeger et al., 1987; Hoeger et al., 1990; Shimano et al., 2006). Hoeger et al. (1990) found that at $80 \%$ of $1 \mathrm{RM}$ test, resistance-trained men were able to perform an average of $\sim 19$ repetitions during leg-press exercises (larger amount of muscle mass), while, at the same intensity, a significant lower number of repetitions was observed for bench press $(\sim 12)$ and arm curl ( 11) exercises (smaller amount of muscle mass). In contrast, Shimano et al., (2006) found no significant differences in the maximum number of repetitions between free weights on back squat $(\sim 7)$ when compared with bench press $(\sim 6)$ and arm curl ( $\sim 6)$ exercices, at the same intensity. On the other hand, no differences were found between the number of repetitions performed in the arm curl and the bech press exercices in both studies (Hoeger et al., 1990; Shimano et al., 2006).

The present study implemented free weights exercises performed in isolated eccentric muscle actions, thus, requiring the participation of two experienced assistants who were responsible to perform the concentric muscle action (returning the bar to the starting position). Therefore, due to methodological difficulties, only the bench press and preacher curl exercises were assessed, so it is not possible to compare our results with the leg press and back squat exercises that were assessed in previous studies as Hoeger et al., (1990) and Shimano et al., (2006), respectively.

Regarding the number of repetitions in the eccentric muscle actions, there is no previous data in the literature, what makes a comparison to studies that used only 1RM not possible. Moreover, it is observed that the number of repetitions between $1 \mathrm{RM}$ and 1RMecc was not significantly different for the bench press and preacher curl exercises. Therefore, the results showed similar responses for the intensities prescribed based on 1RM and 1 RMecc percentages for both exercises.

In order to provide proper training stimuli, strength and conditioning coaches should carefully analyze the complex interactions of training variables (e.g. load intensity, number repetitions, exercise selection, and type of muscle action) when prescribing resistance training. Due to variation of strength eccentric and concentric muscle action, the 1RMecc test should be conducted to determine intensity of eccentric training. Our results support that, when the purpose is to increase of muscular eccentric and concentric strength via bench press and preacher curl exercises, the use of $80 \%$ intensity of $1 \mathrm{RM}$ and 1 RMecc tests is suitable to design resistance training for trained men.

\section{Conclusions}

In conclusion, despite the differences between the absolute load of $80 \%-1 \mathrm{RM}$ and $80 \%$-1RMecc, the maximum number of repetitions performed at the same relative intensity was the same for both exercises. In addition, the maximum number of repetitions may not vary between exercises (single-joint vs. multiple-joint) when the same relative intensity is prescribed. Future research is required to assess the influence of different factors such as the load intensity, exercise selection, velocity of the muscle action, gender, and the training level on the maximum repetitions performance. 


\section{References}

American College of Sports Medicine (2009). Progression models in resistance training for healthy adults. Medicine and Science in Sports and Exercise, 41(3), 687-708.

Bird, S. P., Tarpenning, K. M., \& Marino, F. E. (2005). Designing resistance training programmes to enhance muscular fitness: a review of the acute programme variables. Sports Medicine, 35(10), 41-851.

Brandenburg, J. P., \& Docherty, D. (2002). The effects of accentuated eccentric loading on strength, muscle hypertrophy, and neural adaptations in trained individuals. Journal of Strength and Conditioning Research, 16(1), 25-32.

Brown, L. E., \& Weir, J. P. (2001). ASEP Procedures recommendation I: Accurate assesment of muscular strength and power. Journal of Exercise Physiologyonline, 4(3), 1-21.

Campos, G. E., Luecke, T. J., Wendeln, H. K., Toma, K., Hagerman, F. C., Murray, T. F., . . \& Staron, R. S. (2002). Muscular adaptations in response to three different resistance-training regimens: specificity of repetition maximum zones. European Journal of Applied Physiology, 88(1-2), 50-60.

Enoka, R. M. (1996). Eccentric contractions require unique activation strategies by the nervous system. Journal of Applied Physiology (1948), 81(6), 2339-2346.

Fry, A. C. (2004). The role of resistance exercise intensity on muscle fibre adaptations. Sports Medicine, 34(10), 663-679.

Gentil, P., Oliveira, E., \& Bottaro, M. (2006). Time under tension and blood lactate response during four different resistance training methods. Journal of Physiological Anthropology, 25(5), 339-44.

Hoeger, W., Barette, S. L., Hale, D. F., \& Hopkins D. R. (1987). Relationship between repetitions and selected percentages of one repetition maximum. Journal Applied Sports Science Research, 1, 11-13.

Hoeger, W., Hopkins, D. R., Barette, S. L., \& Hale, D. F. (1990). Relationship between repetitions and selected percentages of one repetition maximum: A comparison between untrained and trained males and females. Journal Applied Sports Science Research, 4, 47-54.

Hollander, D. B., Kraemer, R. R., Kilpatrick, M. W., Ramadan, Z. G., Reeves, G. V., Francois, M., . . \& \& Tryniecki, J. L. (2007). Maximal eccentric and concentric strength discrepancies between young men and women for dynamic resistance exercise. Journal of Strength and Conditioning Research, 21(1), 34-40.

Kraemer, W. J., \& Ratamess, N. A. (2004). Fundamentals of resistance training: progression and exercise prescription. Medicine and Science in Sports and Exercise, 36(4), 674-688.

Sakamoto, A., \& Sinclair P. J. (2006). Effect of movement velocity on the relationship between training load and the number of repetitions of bench press. Journal of Strength and Conditioning Research, 20(3), 523-7.
Shimano, T., Kraemer, W. J., Spiering, B. A., Volek, J. S., Hatfield, D. L., Silvestre, R., . . \& \& Hakkinen, K. (2006). Relationship between the number of repetitions and selected percentages of one repetition maximum in free weight exercises in trained and untrained men. Journal of Strength and Conditioning Research, 20(4), 819-823.

Smith, L. L., Anwar, A., Fragen, M., Rananto, C., Johnson, R., \& Holbert, D. (2000). Cytokines and cell adhesion molecules associated with high-intensity eccentric exercise. European Journal of Applied Physiology, 82(1-2), 61-7.

Roig, M., Macintyre, D. L., Eng, J. J., Narici, M. V., Maganaris, C. N., \& Reid, W .D. (2010). Preservation of eccentric strength in older adults: Evidence, mechanisms and implications for training and rehabilitation. Experimental Gerontology, 45(6), 400-9.

Tan, B. (1999). Manipuling resistance training program variables to optimize maximum strength in men: a review. Journal of Strength and Conditioning Research, 13(3), 239-304.

\section{Authors' note}

\section{Acknowledgments}

We gratefully acknowledge the subjects who dedicated a great deal of time to participate in this study.

\section{Corresponding author}

Charles Ricardo Lopes (chrlopes@unimep.br)

Human Performance Research Group - Methodist University of Piracicaba (UNIMEP). Rodovia do Açúcar, Km 156, s/n, Piracicaba -SP, Brazil.

Manuscript received on February 20, 2013

Manuscript accepted on April 12, 2014

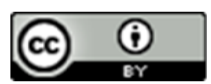

Motriz. The Journal of Physical Education. UNESP. Rio Claro, SP, Brazil - eISSN: 1980-6574 - under a license Creative Commons - Version 3.0 